Chapman University

Chapman University Digital Commons

$10-13-2021$

Romantic Partner Interference and Psychological Reactance in the Context of Caregiving for an Aging Family Member

Hannah Ball

Jennifer L. Bevan

Tessa Urbanovich

Erin S. Craw

Follow this and additional works at: https://digitalcommons.chapman.edu/comm_articles

Part of the Family, Life Course, and Society Commons, Health Communication Commons, Health Psychology Commons, International and Intercultural Communication Commons, Medicine and Health Commons, Other Psychology Commons, and the Theory and Philosophy Commons 
Romantic Partner Interference and Psychological Reactance in the Context of Caregiving for an Aging Family Member

\section{Comments}

This is a pre-copy-editing, author-produced PDF of an article accepted for publication in Journal of Social and Personal Relationships in 2021 following peer review. The definitive publisher-authenticated version is available online at https://doi.org/10.1177/02654075211046244.

\section{Copyright}

The authors 


\title{
Romantic Partner Interference and Psychological Reactance in the Context of Caregiving for an Aging Family Member
}

\author{
Hannah Ball \\ Chapman University \\ Jennifer L. Bevan \\ Chapman University \\ Tessa Urbanovich \\ North Mountain Consulting Group \\ Erin S. Craw \\ Chapman University
}

\begin{abstract}
Author Note
Hannah Ball is an Assistant Professor and Jennifer L. Bevan is a Professor in the School of Communication at Chapman University. Tessa Urbanovich is an alumna of the Health and Strategic Communication M.S. Program at Chapman University and a Research Scientist with the North Mountain Consulting Group. Erin S. Craw is a Ph.D. student in the School of Communication at Chapman University. This research was supported by a grant awarded to the third author by the Chapman University Office of Graduate Studies. A previous version of this manuscript was presented at the 2020 Western States Communication Association convention. Correspondence concerning this article should be addressed to Hannah Ball, One University Drive, Orange, CA 92866. Email: hball@ chapman.edu
\end{abstract}


Romantic Partner Interference and Psychological Reactance in the Context of Caregiving for an Aging Family Member

\begin{abstract}
Negotiating romantic relational dynamics is inherent to family caregiving situations, which continue to be on the rise in the U.S. However, despite evidence that family caregiving duties are linked to a variety of negative relational outcomes, limited research examines communication processes that contribute to or alleviate the burden of caregiver duties on romantic relationships. Guided by psychological reactance theory (PRT), this study examined the link between romantic partner interference with family caregiving duties and the reactance process, as well as directness of communication about irritation as a type of freedom restoration behavior associated with reactance. Adults caring for aging family members recruited from MTurk $(N=187)$ completed an online survey as part of a larger study of romantic partner communication surrounding family caregiving. Results using PROCESS serial mediation indicated that greater partner interference was related to heightened perceptions of freedom threat, which was positively associated with the experience of reactance, which in turn was associated with communication about irritation. However, the association between reactance and directness of communication about irritation was negative, the opposite direction of what was hypothesized. Implications for PRT and interventions with caregivers and their romantic partners are discussed.
\end{abstract}

Keywords: family caregiving, psychological reactance theory, partner interference, romantic relationships, directness of communication 
Romantic Partner Interference and Psychological Reactance in the Context of

Caregiving for an Aging Family Member

The demand for informal caregivers is a growing public health issue in the United States. Approximately 53 million Americans provide informal (i.e., unpaid) care for another individual - the overwhelming majority for an aging family member - an increase from 43.5 million in 2015 (National Alliance for Caregiving/American Association for Retired Persons [NAC/AARP], 2020). Family caregivers provide on average 23.7 hours of care per week and one-third of these caregivers report receiving neither paid nor unpaid help with their caregiving duties (NAC/AARP, 2020). Duties tend to fall within two categories: activities of daily living (ADLs), involving assistance with basic personal needs such as eating, dressing, and bathing; and instrumental activities of daily living (IADLs), entailing help with everyday tasks including shopping for groceries, taking medication, and finance management (Centers for Disease Control and Prevention [CDC], 2009). Individuals who are now in their 20s are estimated to spend approximately five years (or $8.6 \%$ of their remaining life) as caregivers (National Academies of Sciences, Engineering, and Medicine [NASEM], 2016), meaning that the demand for informal caregiving is expected to grow in size and time investment.

Given the time and effort that caregivers devote to their family caregiving role, it is unsurprising that they experience relational burdens. Family caregivers are at increased risk for experiencing loneliness compared to members of the general population (Atlantic Health System/United Way, 2019). Family caregiving can negatively affect the quality of romantic relationships and constrain social interactions (Keating \& Eales, 2017; NASEM, 2016; Penning $\& \mathrm{Wu}, 2018$ ). Approximately $60 \%$ of family caregivers are married or living with a partner 
(NAC/AARP, 2020; NASEM, 2016), suggesting that negotiating romantic relational dynamics is inherent to many caregiving situations.

Toward alleviating these negative consequences to benefit caregivers, the care recipients, and caregivers' relationships alike, public policy has turned its focus to family caregiving (NASEM, 2016). A potential avenue for caregiver interventions may be to learn more about how the family caregiving role affects the dynamics of caregivers' romantic relationships (NASEM, 2016). Given that adopting and inhabiting a family caregiving role has been identified as a potentially turbulent relational transition (Catona, 2019; Knobloch et al., 2020; Solomon, 2016), a partner's interference with caregiving duties may provide a barrier to quality of care as well as relational quality and communication between romantic partners. Indeed, while caring for a family member, married caregivers may spend less time and energy on their romantic relationship, leading to reduced marital satisfaction (Dellmann-Jenkins et al., 2001; Murphy et al., 2015). Given the demands of caregiving, some spouses are unsupportive of their partner's caregiving role (Dellmann-Jenkins et al., 2001; Reczek \& Umberson, 2014; Suitor \& Pillemer, 1994). Prior research demonstrates that when one or both partners serve as a family caregiver, they often experience a decline in marital quality (Bookwala, 2009; Keating \& Eales, 2017) and even relationship dissolution (Penning \& Wu, 2018). In turn, lower marital quality contributes to personal adverse psychological outcomes, such as increased stress and depression (Choi \& Marks, 2006; Reczek \& Umberson, 2016). As the hours spent caregiving increase, caregivers may also face greater feelings of isolation (Li et al., 2021). Further, partner interference (i.e., the extent to which a partner inhibits the other's ability to accomplish activities and goals; Knobloch \& Solomon, 2004) - in the case of the current study, with the caregiving situation - is a specific 
form of partner influence that is linked with relational uncertainty and turbulence (Solomon et al., 2016).

Notably, minimal research has examined the relational effects of caregiver duties and burden on these relationships when the spouse is not the care recipient (e.g., Henz, 2010; Penning \& Wu, 2018). Thus, the current study applies psychological reactance theory (Brehm, 1966; Brehm \& Brehm, 1981) to examine the extent to which family caregivers of an aging relative (i.e., who is not the caregiver's partner or child) perceive their romantic partner's interference with caregiving duties to be restrictive. Results contribute to literature on PRT and caregiving by highlighting the link between a family caregiver's experience of the reactance process and their partner's interference with caregiving duties, as well as emphasizing the importance of each romantic partner aligning caregiving goals and activities upon taking on this caregiving role.

\section{Psychological Reactance Theory}

In addition to specific influences that partner interference with caregiving exerts on romantic partnerships, the caregiving context itself is predisposed to perceptions of constrained autonomy. Indeed, more than half (53\%) of caregivers report feeling like they did not have a choice when taking on caregiving responsibilities (NAC/AARP, 2020). Therefore, there appear to be connections among partner interference with caregiving, caregivers' perceptions that this interference limits their ability to choose how to provide care, and constrained communication between family caregivers and their romantic partners. To further explore these tensions between autonomy and interdependence and how interference may be theoretically linked within this context, we turn to psychological reactance theory. 
Psychological reactance theory (PRT; Brehm, 1966; Brehm \& Brehm, 1981) posits that individuals place great value on their autonomy such that any perceived threats to their autonomy motivate these individuals to restore their sense of freedom. Core to this theory is perceived freedom threat, which occurs when individuals' free behavior (i.e., behaviors they believe to have the right and capacity to engage in at any time) is restricted or eliminated by some influence attempt. For example, the use of domineering and controlling language is well-known to amplify perceptions of freedom threat, whereas choice-enhancing language mitigates these perceptions (see Reynolds-Tylus, 2019; Rosenberg \& Siegel, 2018). Subsequently, individuals experience psychological reactance, which is a combination of anger and negative cognitions (e.g., thoughts of disagreement, resistance, derogation; Dillard \& Shen, 2005) toward the perceived freedom threat (Quick, 2012). To combat reactance, individuals are motivated to engage in freedom restoration behavior, or direct and/or indirect attempts to restore one's sense of autonomy (Brehm, 1966; Reynolds-Tylus, 2019).

The effects of the reactance process have largely been explored in the context of persuasive mass-disseminated health messages; however, evidence indicates that reactance has utility across a variety of communication contexts, including within interpersonal relationships (Palik, 2020; Rosenberg \& Siegel, 2018) and caregiving contexts (Ball, 2016). Although largely external to the caregiver's romantic relationship, becoming a caregiver for an aging family member signifies an ongoing relational transition that can disrupt the interdependence of the partnership (Knobloch et al., 2020; Solomon, 2016) due to changing roles and circumstances for the caregiver, care recipient, and other family members. For example, providing care for a family member entails managing variability in illness trajectories, the care recipient's as well as one's own finances, coordination of care, and eventual end-of-life decisions (NAC/AARP, 2020; 
NASEM, 2016), which as noted above affects a caregiver's romantic relationship. As such, this context is ripe for interpersonal influence attempts with potential connections to reactance.

A relational communication behavior that occurs surrounding these disruptions and may be linked to caregiving reactance through perceived freedom threat is partner interference. Specifically, when the caregiving partner perceives their romantic partner as impeding upon their attempts to perform caregiving duties in a preferred manner - such as disrupting established routines, how much time is devoted to caregiving responsibilities, how responsibilities are negotiated, etc. - they may perceive a threat to their freedom to choose how to provide care, thus inducing reactance. Indeed, partner interference is a type of influence that hinders autonomy and can "make people cognitively and emotionally reactive" (Knobloch et al., 2020, p. 602), the processes at the crux of PRT. More specifically, partner interference is linked to more negative perceptions of transitions in marital relationships (Brisini et al., 2018) and more severe relational irritations (Solomon \& Knobloch, 2004; Theiss \& Solomon, 2006a), but partner interference among caregivers and their partners has not yet been examined (Knobloch et al., 2020). Given that partner interference is linked to similar cognitive and emotional processes as those tied to the reactance process, we propose:

H1: Partner interference with caregiving is related positively to perceived freedom threat.

H2: $\quad$ Perceived freedom threat is related positively to reactance.

When reactance is triggered, individuals engage in freedom restoration behavior to reestablish their sense of autonomy and assuage the effects of reactance (Brehm, 1966). Previous reactance research has revealed that freedom restoration behavior can take a variety of forms, including direct restoration (i.e., rejecting the influence attempt and/or engaging in the opposite 
behavior of what is recommended) and indirect restoration (i.e., vicariously observing others' freedom restoration and/or forming negative perceptions about the message source and message itself; Reynolds-Tylus, 2019). Pertinent to understanding the impact of caregiving-related reactance on romantic relationships is how indirect freedom restoration is often directed at the source of the influence attempt (i.e., one's romantic partner) rather than toward resisting an advocated behavior (i.e., how one's partner thinks care should be provided). Indeed, reactanceinducing interpersonal freedom threats facilitate biased evaluations of an interaction partner (Steindl \& Jonas, 2015). For example, to restore their freedom indirectly, individuals may evaluate the source as less trustworthy (Dillard \& Shen, 2005; Miller et al., 2007) and intend to describe the source to others as incompetent and stubborn (Steindl \& Jonas, 2015). Therefore, within the context of interference with family caregiving, it seems likely that the caregiving partner would engage in freedom restoration behavior directed toward the partner inhibiting caregiving activities.

Although many forms of indirect freedom restoration occur perceptually, they can also transpire communicatively. These freedom restoration attempts tend to involve displays of social dominance (Rosenberg \& Siegel, 2018), such as expressing disagreements or complaints (Ball \& Goodboy, 2014), derogation (Rains, 2013; Miller et al., 2007), anger (Richards \& Larsen, 2017), and hostility (Rosenberg \& Siegel, 2018) toward the source of the influence attempt. As such, a potential form of indirect freedom restoration is an individual's directness of communication about irritation toward their partner about caregiving. Research on communicative directness in personal relationships indicates that the expression of irritations and complaints within a personal relationship is a dominant communication behavior (e.g., Theiss \& Solomon, 2006a; Worley \& Samp, 2016), and dominant communication behavior is associated with greater perceptions of 
one's own level of power in a relationship (Dunbar \& Burgoon, 2005). It follows that the experience of reactance may be linked to more direct communication - rather than avoidance about irritations relevant to caregiving interference to restore perceptions of one's autonomy and control. Also relevant to the current context, greater caregiving partner interference is associated with greater communicative directness (Checton et al., 2012; Theiss \& Solomon, 2006a); reactance may function as an explanatory mechanism. Thus, the following hypothesis was proposed:

H3: Reactance is related positively to directness of communication about irritation related to caregiving.

Following the two-step model of reactance (Quick \& Considine, 2008; Quick \& Stephenson, 2008; see Figure 1), the reactance process begins with an antecedent (i.e., partner interference with caregiving) that triggers a perceived threat to one's freedom, which subsequently prompts the experience of psychological reactance. Moreover, because reactance motivates individuals to restore their sense of freedom (Brehm, 1966), the experience of reactance should be related to freedom restoration behavior (i.e., directness of communication about irritation with caregiving interference). Formally stated:

H4: There is an indirect association between partner interference with caregiving and directness of communication about irritation sequentially through perceived freedom threat and reactance.

\section{Method}

\section{Participants and Procedures}

Participants were 187 unpaid caregivers for an aging family member with a health condition (e.g., diabetes, cancer, mental health issue) who was not their spouse, and who were 
involved in a romantic relationship while serving as caregiver (see Table 1 for demographics). All participants resided in the U.S. At the time of data collection, most participants were currently serving as caregivers $(n=159 ; 28$ no longer provided care). Current caregivers for an aging family member as well as those who are not currently caregivers but provided care within the past year were included in the sample due to the similarities between how these two groups assign meaning to their care experiences up to three years after caregiving ceases (Halliwell et al., 2001; Robinson-Whelen et al., 2001). Results of independent samples $t$-tests indicated no significant differences between these two groups on the main study variables. Participants were in the caregiving role for an average length of 3.79 years $(S D=3.67)$, provided care for an average of 13.41 hours per week $(S D=15.23)$, and reported that their romantic partners provided an average of 7.01 hours per week of care (range: $0-72 ; S D=11.75$ ), with only one-third of participants $(33.16 \%)$ reporting that their partners provided zero hours per week of care.

Amazon MTurk hosted an online Qualtrics survey as part of a larger study on romantic partner communication regarding caring for an aging family member. To prevent non-family caregivers from accessing the study, the study description was intentionally broad: "Health Communication in Romantic and Family Relationships.” MTurk workers responded to a screening question about their relationship status and caregiving status from a list of seven options including a "none of the above" option. Only those who selected the option "I'm in a romantic relationship and I help care for an aging family member who is not my partner" entered the survey. Out of the 1631 members of the MTurk community who responded to the screening question, 1405 workers $(86.14 \%)$ did not meet the initial screening criteria and therefore were not redirected to the full survey. 
Per previous research suggesting that caregivers often do not define themselves by that term (e.g., Amaro, 2015), the term "caregiver" was avoided in recruiting materials, the screening question, nor very minimally in the consent form. The survey included attention check items, and data were checked thoroughly to validate that participants were caregivers. Data for 39 participants were removed because participants did not adequately address attention check items, resulting in a final sample of 187 participants. MTurk workers who successfully completed the anonymous, 15-minute study received $\$ .90$ compensation. Recruitment methods and study procedures received IRB exemption by the host university.

Upon qualification and entrance to the survey, participants provided consent and then were directed to read the following description of a family caregiver as a formal introduction to the questionnaire:

We define a family caregiver as someone who provides unpaid assistance and care to an aging family member who has a health problem, disability, or a long-term illness.

This assistance can include personal and medical care, as well as household chores, managing the family member's finances, and/or arranging for outside services. This family member cannot be your own romantic partner or child, for the purposes of this study.

As they completed the survey, participants were asked to think of interactions with their romantic partner about the care recipient's health and the overall caregiving situation.

\section{Instrumentation}

Partner interference. To measure partner interference with caregiving responsibilities, participants rated their agreement on a 5-item Likert scale developed by Knobloch and Solomon (2004). These items were adapted to refer to interference with caregiving responsibilities (e.g., 
"My romantic partner makes it harder for me to schedule my caregiving activities" and "My partner interferes with how much time I devote to caregiving”). Items were rated on a scale from $1=$ strongly disagree to $7=$ strongly agree $(M=2.96, S D=1.94, \alpha=.97)$.

Perceived freedom threat. Dillard and Shen's (2005) four-item scale assessed perceived freedom threat. Items were adapted to refer to romantic partners' perceived threat related to choosing how to provide care to the care recipient (e.g., "My partner tries to make decisions for me regarding how to provide care" and "My partner threatens my freedom to choose how to provide care"; 1 = strongly disagree to $7=$ strongly agree $(M=2.76, S D=1.78, \alpha=.94)$.

Reactance. Following Quick (2012) and Rosenberg and Siegel (2018), reactance was operationalized as a combination of anger and negative cognitions. Anger was measured using Dillard and Peck's (2000) scale, adapted to rate the degree to which four specific emotions were experienced during partners' communication about caregiving (e.g., irritated, annoyed; $1=$ not at all; 7 = extremely). Participants' negative cognitions about their partners' communication about caregiving were measured using four items from Dillard et al. (1996) and Miller et al. (2007) and adapted to the current context (e.g., "In conversations about providing care, how my partner communicates gets in the way of what I want"; 1 = strongly disagree 7 = strongly agree $)$. Similar to previous research (e.g., Ball \& Goodboy, 2014; Shen, 2010), a composite reactance score was created by summing the scores for anger and negative cognitions $(M=21.21, S D=$ $10.76, \alpha=.86)$

Directness of communication about irritation. To measure directness of communication about irritation related to caregiving, participants rated their agreement on a four-item Likert scale ranging from 1 = strongly disagree to 7 = strongly agree developed by Theiss and Solomon (2006a). Participants were asked to respond to these items in regard to 
conversations with their romantic partner about caregiving. Example items include "When I was irritated by my partner's behavior, I confronted him/her directly" and "I have explicitly told my partner about behaviors that irritate me" $(M=4.37, S D=1.68, \alpha=.91)$.

Covariates. Characteristics of the romantic relationship and caregiving situation were considered as covariates. Covariates entered into the model included relational satisfaction, caregiver gender identity $(1=$ woman, $0=$ man $)$, current marital status $(1=$ married, $0=$ not married), number of hours per week spent providing care, whether one's partner provides care during a given week $(1=$ yes, $0=$ no), caregiving status (i.e., whether the participant was currently serving as a family caregiver; $1=$ current, $0=$ former), and number of family members providing care. Caregivers' relational satisfaction with their romantic partner was measured using Rusbult et al.'s (1998) 6-item Likert scale ranging from $1=$ strongly disagree to $7=$ strongly agree (e.g., "My relationship is close to ideal" and "I feel satisfied in our relationship"; $M=5.45, S D=1.32, \alpha=.93)$. For hours per week spent providing care, participants were asked to enter the number of hours per week they typically spend providing care to the care recipient and then separately the number hours per week their romantic partner typically spends providing care to the care recipient. For number of family members providing care, participants were asked to provide a number that included family members “providing care and those who don't, but who are still involved (e.g., those who receive updates, live far away, only contribute financially, etc.)."

\section{Results}

\section{Primary Analysis}

Correlations for all variables of interest can be found in Table 2. H1 to H4 were tested via serial mediation (i.e., sequential multiple mediation) using Model 6 from the PROCESS macro in 
SPSS, which utilizes ordinary least squares path analysis to test for direct and indirect effects within the proposed model (Hayes, 2018; see Figure 1). We used percentile bootstrapped standard errors and 95\% confidence intervals from 5,000 resamples to examine the indirect effects, and confidence intervals not containing zero were interpreted as statistically significant (Hayes, 2018). See Table 3 for model summary statistics including unstandardized path coefficients.

H1 predicted that partner interference with caregiving would be related positively to perceived freedom threat. Controlling for the covariates (i.e., relationship satisfaction, caregiver gender, marital status, hours per week spent providing care, whether one's partner provides care during a given week, current caregiving status, and number of family members providing care), results supported H1 $\left(a_{1}=.80, S E=.04, t=22.49, p<.001,95 \%\right.$ CI $\left.[.73, .87]\right)$ such that partner caregiving interference was positively related to perceived freedom threat. Notably, two covariates emerged as significant contributors to this relationship. First, greater number of hours per week spent providing care was associated with lower perceptions of freedom threat $($ coefficient $=-.01, S E=.00, t=-3.03, p=.003,95 \% \mathrm{CI}[-.02,-.01])$. Additionally, greater perceptions of freedom threat were reported in caregiving situations in which romantic partners helped provide care during a given week $(M=3.00, S D=1.74)$ versus those in which partners did not provide care $(M=2.28, S D=1.80$; coefficient $=.41, S E=.14, t=3.00, p=.003,95 \% \mathrm{CI}$ $[.14, .69])$

$\mathrm{H} 2$ predicted that perceived freedom threat would be related positively to reactance. Controlling for the covariates, this hypothesis was supported $\left(d_{21}=2.51, S E=.63, t=3.99, p<\right.$ $.001,95 \%$ CI $[1.27,3.76])$, revealing a positive relationship between perceived freedom threat and reactance. One covariate emerged as a significant contributor to this relationship: greater 
relationship satisfaction was related to a lower experience of reactance (coefficient $=-2.99, S E=$ $.43, t=-6.93, p<.001,95 \%$ CI $[-3.84,-2.14])$.

$\mathrm{H} 3$ predicted that reactance would be related positively to directness of communication about irritation. This hypothesis was not supported; although there was a significant relationship between reactance and directness of communication about irritation when controlling for the covariates, this relationship was in the opposite direction than was predicted $\left(b_{2}=-.04, S E=.02\right.$, $t=-2.33, p=.02,95 \% \mathrm{CI}[-.08,-.01])$. One covariate emerged as a significant contributor to this relationship: greater directness of communication about irritation was reported among participants who identified as a woman $(M=4.59, S D=0.16)$ than participants who identified as a $\operatorname{man}(M=4.07, S D=0.19$; coefficient $=.63, S E=.25, t=2.55, p=01,95 \%$ CI $[.14,1.12])$.

$\mathrm{H} 4$ posited that there would be an indirect effect of partner interference on directness of communication about irritation sequentially through perceived freedom threat and reactance. H4 was supported; controlling for the covariates, results revealed a significant indirect effect $\left(a_{1} d_{21} b_{2}=-.08, S E=.05,95 \%\right.$ bootstrapped CI [-.19, -.01]). In other words, individuals reporting greater partner caregiving interference perceived a greater threat to their freedom, which in turn was associated with increased reactance, and increased reactance was associated with decreased directness of communication about irritation.

\section{Post Hoc Analysis}

Due to the unexpected negative direction of the relationship between reactance and directness of communication about irritation (H3), a post hoc analysis was performed to examine the direction and significance of this relationship with the covariates removed from the model. Results of a serial mediation analysis revealed that with covariates removed, reactance was not 
significantly related to directness of communication about irritation (coefficient $=-.03, S E=.02$, $t=-1.96, p=.05,95 \%$ CI $[-.06, .00])$.

\section{Discussion}

Toward addressing the paucity of research on how assuming the family caregiving role affects romantic relational dynamics, this study investigated the reactance process as it stems from romantic partner interference with caring for an aging family member. As predicted, results revealed that partner interference with caregiving was related to perceived freedom threat, which was associated with the experience of reactance. Additionally, reactance was associated with directness of communication about irritation regarding caregiving. However, the association between reactance and communicative directness was negative, which was the opposite of our prediction. Implications for PRT, research on partner interference and communicative directness, and interventions with caregivers and their romantic partners are detailed in the following sections.

Findings for $\mathrm{H} 1, \mathrm{H} 2$, and $\mathrm{H} 4$ yield implications for reactance theory as well as research on partner inference as a form of partner influence. First, results indicate that the PRT framework can be applied to the interpersonal dynamics between romantic partners within the context of caregiving for an aging family member. Although reactance literature within health communication has largely considered persuasive campaign messages, the current study reinforces the utility of PRT to interpersonal influence attempts (see Ball, 2016; Palik, 2020; Steindl \& Jonas, 2015) and confirms Steindl et al.'s (2015) supposition that there may be instances where individuals perceive their romantic partner to be freedom-threatening.

Additionally, our findings add romantic partner caregiving interference to the list of influence attempts linked to the reactance process. These results are also consistent with previous 
reactance research that suggests individuals prefer to be reminded of their ability to act autonomously (e.g., Bessarabova et al., 2013; Miller et al., 2007; Shen, 2015) rather than receiving directives that they must behave (in this case, provide care) in a certain manner (e.g., Dillard \& Shen, 2005; Quick \& Considine, 2008). Finally, the results allow us to discern reactance as one of the various cognitive and emotional attributes within the "reactive environment" surrounding partner interference (Theiss \& Solomon, 2006b, p. 494).

Although partner interference is not inherently negative (Knobloch \& Solomon, 2004), it appears that when caring for an aging relative, reactance is an explanatory function through which romantic partner interference is associated with undesirable relational processes. Indeed, we found that the caregiving partner interprets interference from their romantic partner as imposing upon their ability to autonomously provide care, resulting in the experience of negative thoughts and emotions toward their partner. Given this negative face threat, an interesting next step would be to consider the current results in combination with Palik's (2020) findings that unsolicited advice is perceived as freedom-threatening under certain circumstances; for example, whereas the provision of unsolicited advice might be perceived to be freedom-threatening when the recipient is not receptive to the advice, recipients who are receptive may perceive no difference between unsolicited and solicited advice.

Although the current results indicate that greater levels of partner interference are associated with greater perceptions of freedom threat, circumstances under which providing caregiving advice does not contribute to reactance are likely to exist. For example, it may be that reactance is less of a concern among family caregivers who are low in trait reactance (Miller et al., 2007; Quick \& Stephenson, 2008) and locus of control (Xu, 2017). Conversely, individuals with the tendency to communicate rather than suppress anger experience heightened reactance 
(Richards \& Larsen, 2017). As such, future research should consider not only the extent to which caregivers are receptive to or seek caregiving advice or guidance from their relational partner, but also identify individual characteristics that make caregivers more or less likely to perceive partner interference as reactance-inducing.

Given that partner interference with caregiving emerged as an antecedent of the reactance process, future research should also explore the specific sources from which partner interference stems. For example, Catona (2019) identified four specific sources of partner interference within older adult marriages in which one spouse has Alzheimer's disease, including being forced to take on additional roles and responsibilities; managing an overwhelming burden of care; feeling socially isolated; and sacrificing future plans, such as those related to retirement. It would be useful to ascertain the specific sources of romantic partner interference in the context of caregiving for an aging family member and whether any of these sources are associated with a relatively larger experience of reactance, as the magnitude of reactance is influenced by the personal importance of a threatened behavior (Reynolds-Tylus, 2019).

The finding for $\mathrm{H} 3$ is intriguing in that the link between reactance and directness of communication about the irritation was negative, opposite of the prediction. Although reactance and communicative directness were positively correlated, consistent with related research (e.g., Checton et al., 2012; Theiss \& Solomon, 2006a), this relationship became negative when entered into the serial mediation model. Moreover, results of the post hoc analysis revealed that this relationship was no longer significant when the specific set of covariates entered into the full serial mediation model were removed. Ultimately, we found that experiencing reactance in response to freedom threat and partner caregiving interference regarding an aging family member's health and care is associated with less direct communication about irritation related to 
the issue. The difference may lie in the context of the caregiving situation, which is timeconsuming and often a mental and physical burden for the caregiver (e.g., NAC/AARP, 2020). Caregiving-related topic avoidance occurs at moderate levels between long distance family caregivers and their care recipients (Bevan et al., 2012), suggesting such avoidance may also be a response to reactance by family caregivers toward their romantic partners to restore feelings of autonomy. Additionally, reactance research suggests that individual differences in suppression and communicative expression of anger affect how reactance is processed (Richards \& Larsen, 2017). Future research is needed to examine these possibilities.

Also notable is that Theiss and Solomon (2006a) found that directness of communication about irritation is "subject to a diversity of influences" (p. 408). Although the relationship between reactance and communicative directness is important to consider, perhaps the significant negative relationship that emerged between these two variables can be explained by the set of covariates included in the model, further evidenced by the results of the post hoc analysis. For instance, we found that caregiver gender identity significantly contributed to the relationship between reactance and communication directness. Perhaps this result can be attributed to how women are socialized to place higher value upon open, explicit forms of communication in relationships than men, and therefore tend to favor it over avoidance (Merrill \& Afifi, 2012).

Regardless of the direction of the result, (in)directness of communication about irritation emerging as a behavior that family caregivers engage with romantic partners to restore their freedom following the experience of reactance extends PRT. Indeed, most reactance research has limited its operationalization of freedom restoration behavior to general attitudes and behavioral intentions related to an influence attempt. Therefore, the current results add to the growing list of freedom restoration behaviors, including decreased trust and increased anger toward a message 
source (Bessarabova et al., 2017) and lower perceptions of advice usefulness (Palik, 2020).

Future research should consider variables beyond communicative directness that would yield a fuller picture about how reactance facilitates both approach and avoidance responses to regaining autonomy after experiencing reactance toward partner interference with caregiving, such as the demand/withdraw conflict pattern, topic avoidance and declaring topics taboo, and the chilling effect (i.e., withholding relational complaints from a controlling partner; Cloven \& Roloff, 1993).

Given that partner interference is one of three relationship parameters (i.e., in addition to relationship uncertainty and partner facilitation) that shape how relational partners navigate turbulent life transitions (e.g., Brisini et al., 2018; Solomon et al., 2016), future research should also consider how relational turbulence theory (RTT; Solomon et al., 2016) can be applied to the caregiving context. As previously mentioned, taking on a caregiving role is a potentially turbulent relational transition (Catona, 2016; Solomon, 2016), warranting RTT exploration from the perspectives of the primary family caregiver, secondary caregiver(s), and care recipient alike. For instance, researchers could examine how RTT helps explain family caregiving relational dynamics during shifts due to illness trajectories and assumption of palliative care. Additionally, taking into consideration the call to apply RTT to our understanding of how individuals' personal identities transform relative to a life transition (Solomon, 2016), researchers could examine how family caregivers of an aging relative negotiate their identity as a caregiver after their role ends.

\section{Practical Implications}

Results of the current study yield implications for caregivers and their relationships. First and foremost, the results suggest that couples likely need preparation for the relational transition they will undergo when one partner assumes a caregiving role for an aging family member, as 
partner interference with caregiving is related to negative cognitions and emotions toward that partner. Partners should be encouraged to be a coordinated team and align their caregiving goals or activities to reduce perceptions of partner interference, thereby circumventing the reactance process. Certain communication activities lessen perceptions of partner interference and help married couples navigate through life transitions (Brisini et al., 2018). However, in situations where romantic partners must provide caregiving directives or assist in caregiving duties, they should carefully consider their communication tactics, as perceptions of freedom threat are associated with reactance. Moreover, greater freedom threat was reported across instances in which the partner helps provide care during a given week than those in which the partner does not help with caregiving. Following Miller et al. (2007), caregiving-related influence messages from the partner should emphasize choice and include autonomy-supporting language such as “perhaps," "possibly,” and "might want to." Partners could also identify certain caregiving duties where the caregiving partner is receptive to advice (Palik, 2020) and interfere only in those situations. Finally, romantic partners can speak to the caregiving partner's altruism for taking on this role and remind them how much they care about the aging family member, as selftranscendence values can attenuate reactance (Han \& Kim, 2019).

From the caregiver's perspective, it is important to be aware of one's own proclivity to experiencing reactance toward a romantic partner's interference with care, especially given that individuals who are high in trait reactance experience greater freedom threats across contexts (Reynolds-Tylus, 2019). Our findings suggest that characteristics of the caregiving situation are associated with varying experiences of the reactance process. First, perceived freedom threat toward partner interference with caregiving decreases as hours spent caregiving each week increase and is also more likely among caregivers whose partner takes on a secondary caregiver 
role than those whose partner does not help provide care. Given that the number of hours per week spent caregiving places a substantial amount of negative emotional burden on caregivers (Cook et al., 2018) and tends to be higher among caregivers who feel like they had no choice in taking on this role (NAC/AARP, 2020), it appears that these caregivers may already experience freedom threat toward the caregiving role itself, thereby perceiving partner interference with caregiving as less severe in comparison. Moreover, it may be that situations in which a partner helps with caregiving duties provide increased opportunities for partner interference and difficulties with care coordination. Second, our finding that greater relationship satisfaction with one's romantic partner is associated with lower levels of reactance among caregivers is promising, as it suggests that relationship satisfaction may be a potential buffer between perceiving partner interference with caregiving as a freedom threat and experiencing anger/negative cognitions toward one's partner.

At the same time, any communication-based training or interventions with caregivers and their romantic partners should not overlook the needs of romantic partners who are tasked with the role of secondary caregiver for an aging family member (67\% of our sample). Although secondary caregivers provide fewer hours of care than primary caregivers (Marino et al., 2020), they report similar levels of emotional and physical strain - particularly when the care recipient is a parent (Marino et al., 2020). Moreover, although researchers have found statistically significant differences between the two types of caregivers regarding their levels of caregiver burden (e.g., Bédard et al., 2001; Gonçalves-Pereira et al., 2020), the level of burden that secondary caregivers experience is still considered "severe" and is accompanied by anxiety and depressive symptoms comparable to those of primary caregivers (Gonçalves-Pereira et al., 2020). 
To strengthen the efficacy of this caregiving unit, caregiving research and interventions should place greater emphasis on understanding secondary caregivers' goals and needs.

\section{Limitations}

This study is not without limitations. First, although the order of the paths for the serial mediation model was driven by PRT, the model was tested using cross-sectional self-report data; as such, causality cannot be claimed. Future research employing longitudinal data collection would be a welcome addition to the PRT literature. Second, given that $53 \%$ of informal caregivers report feeling like they did not have a choice when taking on caregiving responsibilities - a percentage that increases as number of years spent caregiving increases (NAC/AARP, 2020) - it may be the case that the caregivers' perceptions of the caregiving role itself contributed to their reports of freedom threat, thereby reflecting other instances of lack of choice (e.g., not being able to spend time with one's partner due to caregiving responsibilities) rather than partner interference alone. Third, although MTurk has been previously validated as a tool to obtain self-report survey data in social science research (Buhrmester et al., 2011), the current study's sample was predominately White and reported providing below the national average number of hours of care per week, potentially limiting the generalizability of our results. Finally, we obtained a strong correlation $(r=.89)$ between partner interference and perceived freedom threat. Although VIF and tolerance values among all focal predictor variables suggested that multicollinearity was not an issue, variance of the coefficient estimates may have been affected.

\section{Conclusion}

The interplay between assuming a family caregiving role and romantic relational dynamics is important to consider but often overlooked, as evidenced by the lack of research on 
this perspective of the caregiving situation (e.g., Henz, 2010; Penning \& Wu, 2018). The current study begins to fill this gap in revealing that romantic partner interference with caregiving duties is associated with the reactance process - including the experience of negative cognitions and emotions toward the romantic partner - which is linked to the caregiving partner behaving in a way that restores their sense of control. Further research on shifts in relational dynamics between romantic partners throughout this potentially disruptive (Brisini et al., 2018; Solomon, 2016) relational transition could yield valuable insight for communication-based caregiving training for the romantic partners as a dyad. 


\section{References}

Amaro, L. M. (2015). Convincing family caregivers to participate in research: "Does that count as caregiving?" Journal of Applied Communication Research, 43, 269-272. http://doi.org/10.1080/00909882.2015.1019547

Atlantic Health System/United Way. (2019). Family caregivers: A community in crisis. Retrieved from https://www.unitedwaynnj.org/caregiverhealth

Ball, H. (2016). Applying psychological reactance theory to communication between adult child caregivers and their older adult parents (Publication No. 10146595) [Doctoral dissertation, West Virginia University]. ProQuest Dissertations Publishing.

Ball, H., \& Goodboy, A. K. (2014). An experimental investigation of the antecedents and consequences of psychological reactance in the college classroom. Communication Education, 63(3), 192-209. https://doi.org/10.1080/03634523.2014.918634

Bédard, M., Raney, D., Molloy, D. W., Lever, J., Pedlar, D., \& Dubois, S. (2001). The experience of primary and secondary caregivers caring for the same adult with Alzheimer's disease. Journal of Mental Health and Aging, 7, 287-296.

Bessarabova, E., Fink, E. L., \& Turner, M. (2013). Reactance, restoration, and cognitive structure: Comparative statics. Human Communication Research, 39, 339-364. http://doi.org/10.1111/hcre.12007

Bessarabova, E., Miller, C. H., \& Russell, J. (2017). A further exploration of the effects of restoration postscripts on reactance. Western Journal of Communication, 81, 385-403. http://doi.org/10.1080/10570314.2016.1254815 
Bevan, J. L., Rogers, K. E., Andrews, N. F., \& Sparks, L. (2012). Topic avoidance and negative health perceptions in the distant family caregiving context. Journal of Family Communication, 12, 300-314. https://doi.org/10.1080/15267431.2012.686942

Bookwala, J. (2009). The impact of parent care on marital quality and well-being in adult daughters and sons. Journal of Gerontology: Psychological Sciences, 64B, 339-347. http://doi.org/10.1093/geronb/gbp018

Brehm, J. W. (1966). A theory of psychological reactance. Academic Press.

Brehm, S. S., \& Brehm, J. W. (1981). Psychological reactance: A theory of freedom and control. Academic Press.

Brisini, K. S. C., Solomon, D. H., \& Nussbaum, J. (2018). Transitions in marriage: Types, turbulence, and transition processing activities. Journal of Social and Personal Relationships, 35, 831-853. http://doi.org/10.1177/0265407517699283

Buhrmester, M., Kwang, T., \& Gosling, S. D. (2011). Amazon’s Mechanical Turk: A new source of inexpensive, yet high-quality, data? Perspectives on Psychological Science, 6, 3-5. http://doi.org/10.1177/1745691610393980

Catona, D. (2019). "We have been robbed of the life we planned": Relational turbulence and experiences of Alzheimer's disease. In J. A. Theiss \& K. Greene (Eds.), Contemporary studies on relationships, health, and wellness: Advances in personal relationships (pp. 139-159). Cambridge University Press.

Centers for Disease Control and Prevention (CDC). (2009). Limitations in activities of daily living and instrumental activities of daily living, 2003-2007. Retrived from http://www.cdc.gov/nchs/health_policy/ADL_tables.htm 
Checton, M., Greene, K., Magsamen-Conrad, K., \& Venetis, M. (2012). Patients' and partners' perspectives of chronic illness and its management. Families, Systems, \& Health, 30, 114-129. http://doi.org/10.1037/a0028598

Choi, H., \& Marks, N. F. (2006). Transition to caregiving, marital disagreement, and psychological well-being: A prospective U.S. national study. Journal of Family Issues, 27(12), 1701-1722. http://doi.org/10.1177/0192513X06291523

Cloven, D. H., \& Roloff, M. E. (1993). The chilling effect of aggressive potential on the expression of complaints in intimate relationships. Communication Monographs, 60, 199219. http://doi.org/10.1080/03637759309376309

Cook, S. K., Snellings, L., \& Cohen, S. A. (2018). Socioeconomic and demographic factors modify observed relationship between caregiving intensity and three dimensions of quality of life in informal adult children caregivers. Health and Quality of Life Outcomes, 16, 1-12. http://doi.org/10.1186/s12955-018-0996-6

Dellmann-Jenkins, M., Blankemeyer, M., \& Pinkard, O. (2001). Incorporating the elder caregiving role into the developmental tasks of young adulthood. International Journal of Aging and Human Development, 52, 1-18. http://doi.org/10.2190/FGQA-65FU-JGNT$\underline{6 \mathrm{C} 9 \mathrm{~J}}$

Dillard, J. P., Kinney, T., \& Cruz, M. G. (1996). Influence, appraisals, and emotions in close relationships. Communication Monographs, 63, 105-130. http://doi.org/10.1080/03637759609376382.

Dillard, J. P., \& Peck, E. (2000). Affect and persuasion: Emotional responses to public service announcements. Communication Research, 27, 461-495. http://doi.org/10.1177/009365000027004003 
Dillard, J. P., \& Shen, L. (2005). On the nature of reactance and its role in persuasive health communication. Communication Monographs, 72, 144-168. http://doi.org/10.1080/03637750500111815

Dunbar, N. E., \& Burgoon, J. K. (2005). Perceptions of power and interactional dominance in interpersonal relationships. Journal of Social and Personal Relationships, 22, 207-233. http://doi.org/10.1177/0265407505050944

Gonçalves-Pereira, M., Zarit, S. H., Cardoso, A. M., Alves da Silva, J., Papoila, A. L., \& Mateos, R. (2020). A comparison of primary and secondary caregivers of persons with dementia. Psychology and Aging, 35, 20-27. http://doi.org/10.1037/pag0000380

Halliwell, D., Wenzel Egan, K. A., \& Howard, E. L. (2017). Flying in a V formation: themes of (in)equity, reality, and togetherness in adult siblings' narrative explanations of shared parental caregiving. Journal of Applied Communication Research, 45(3), 256-273. http://doi.org/10.1080/00909882.2017.1320574

Han, K. J., \& Kim, S. (2019). Toward more persuasive diabetes messages: Effects on personal value orientation and freedom threat on psychological reactance and behavioral intention. Journal of Health Communication, 24, 95-110. http://doi.org/10.1080/10810730.2019.1581304

Hayes, A. F. (2018). Introduction to mediation, moderation, and conditional process analysis: A regression-based approach (2nd ed.). Guilford Press.

Henz, U. (2010). Parent care as unpaid family labor: How do spouses share? Journal of Marriage and Family, 72, 148-164. http://doi.org/10.1111/j.1741-3737.2009.00689 
Keating, N., \& Eales, J. (2017). Social consequences of family care of adults: A scoping review. International Journal of Care and Caring, 1, 153-173. http://doi.org/10.1332/239788217X14937990731749

Knobloch, L. K., Nichols, L. O., \& Martindale-Adams, J. (2020). Applying relational turbulence theory to adult caregiving relationships. Gerontologist, 60, 598-606. http://doi.org/10.1093/geront/gnz090

Knobloch, L. K., \& Solomon, D. H. (2004). Interference and facilitation from partners in the development of interdependence within romantic relationships. Personal Relationships, 11, 115-130. http://doi.org/10.1111/j.1475-6811.2004.00074.x

Li, L., Wister, A. V., \& Mitchell, B. (2021). Social isolation among spousal and adult-child caregivers: Findings from the Canadian longitudinal study on aging. The Journals of Gerontology: Series B, Psychological Sciences and Social Sciences, 76(7), 1415-1429. http://doi.org/10.1093/geronb/gbaa197

Marino, V. R., Badana, A. N. S., \& Haley, W. E. (2020). Care demands and well-being of primary and secondary non-spousal caregivers of aging adults. Clinical Gerontologist, 43(5), 558-571. http://doi.org/10.1080/07317115.2020.1759748

Merrill, A. F., \& Afifi, T. D. (2012). Examining the bidirectional nature of topic avoidance and relationship dissatisfaction: The moderating role of communication skills. Communication Monographs, 79(4), 499-521. http://doi.org/10.1080/03637751.2012.723809

Miller, C. H., Lane, L. T., Deatrick, L. M., Young, A. M., \& Potts, K. A. (2007). Psychological reactance and promotional health messages: The effects of controlling language, lexical 
concreteness, and the restoration of freedom. Human Communication Research, 33, 219240. http://doi.org/10.1111/j.1468-2958.2007.00297.x

Murphy, J. S., Nalbone, D. P., Wetchler, J. L., \& Edwards, A. B. (2015). Caring for aging parents: The influence of family coping, spirituality/religiosity, and hope on the marital satisfaction of family caregivers. American Journal of Family Therapy, 43, 238-250. http://doi.org/10.1080/01926187.2015.1034636

National Academies of Sciences, Engineering, and Medicine (NASEM). (2016). Families caring for an aging America. The National Academies Press.

National Alliance for Caregiving/American Association for Retired Persons (NAC/AARP). (2020). 2020 report: Caregiving in the U.S. Retrieved from https://www.caregiving.org/wpcontent/uploads/2020/06/AARP1316_RPT_CaregivingintheUS_WEB.pdf

Palik, J. E. (2020). The contextual effects of advice solicitation on advice outcomes: The role of perceived face threats and psychological reactance. Communication Monographs, 87(1), 70-91. http://doi.org/10.1080/03637751.2019.1641729

Penning, M. J., \& Wu, Z. (2018). Caregiving and union instability in middle and later life. Journal of Marriage and Family, 81, 79-98. http://doi.org/10.1111/jomf.12534

Quick, B. L. (2012). What is the best measure of psychological reactance? An empirical test of two measures. Health Communication, 27, 1-9. $\underline{\text { http://doi.org/10.1080/10410236.2011.567446 }}$

Quick, B. L., \& Considine, J. R. (2008). Examining the use of forceful language when designing exercise persuasive messages for adults: A test of conceptualizing reactance arousal as a 
two-step process. Health Communication, 23, 483-491.

http://doi.org/10.1080/10410230802342150

Quick, B. L., \& Stephenson, M. T. (2008). Examining the role of trait reactance and sensation seeking on perceived threat, state reactance, and reactance restoration. Human Communication Research, 34, 448-476. http://doi.org/10.1111/j.1468-2958.2008.00328.x

Rains, S. A. (2013). The nature of psychological reactance revisited: A meta-analytic review. Human Communication Research, 39, 47-73. http://doi.org/10.1111/j.1468$\underline{2958.2012 .01443 . x}$

Reczek, C., \& Umberson, D. (2016). Greedy spouse, needy parent: The marital dynamics of gay, lesbian, and heterosexual intergenerational caregivers. Journal of Marriage \& Family, 78, 957-974. http://doi.org/10.1111/jomf.12318

Reynolds-Tylus, T. (2019). Psychological reactance and persuasive health communication: A review of the literature. Frontiers in Communication, 4, 1-12. http://doi.org/10.3389/fcomm.2019.00056

Richards, A. S., \& Larsen, M. (2017). Anger expression moderates the effects of psychological reactance to sexual health messages. Health Communication, 32, 1491-1500. http://doi.org/10.1080/10410236.2016.1230811

Robinson-Whelen, S., Tada, Y., MacCallum, R. C., McGuire, L., \& Kiecolt-Glaser, J. (2001). Long-term caregiving: What happens when it ends? Journal of Abnormal Psychology, 110(4), 573-584, http://doi.org/10.1037//0021-843X.110.4.573

Rosenberg, B. D., \& Siegel, J. T. (2018). A 50-year review of psychological reactance theory: Do not read this article. Motivation Science, 4, 281-300. http://doi.org/10.1037/mot0000091 
Rusbult, C. E., Martz, J. M., \& Agnew, C. R. (1998). The Investment Model Scale: Measuring commitment level, satisfaction level, quality of alternatives, and investment size. Personal Relationships, 5, 357-391. http://doi.org/10.1111/j.1475-6811.1998.tb00177.x

Shen, L. (2010). Mitigating psychological reactance: The role of message-induced empathy in persuasion. Human Communication Research, 36, 397-422. http://doi.org/10.1111/j.1468-2958.2010.01381.x

Shen, L. (2015). Antecedents to psychological reactance: The impact of threat, message frame, and choice. Health Communication, 30, 975-985. http://doi.org/10.1080/10410236.2014.910882

Solomon, D. H. (2016). Relational turbulence model. In C. R. Berger \& M. E. Roloff (Eds.), The international encyclopedia of interpersonal communication (pp. 1460-1468). Wiley.

Solomon, D. H., \& Knobloch, L. K. (2004). A model of relational turbulence: The role of intimacy, relational uncertainty, and interference from partners in appraisals of irritations. Journal of Social and Personal Relationships, 21, 795-816. http://doi.org/10.1177/0265407504047838

Solomon, D., Knobloch, L., Theiss, J., \& McLaren, R. (2016). Relational turbulence theory: Explaining variation in subjective experiences and communication within romantic relationships. Human Communication Research, 42, 507-532. http://doi.org/10.1111/hcre.12091

Steindl, C., \& Jonas, E. (2015). The dynamic reactance interaction - How vested interests affect people's experience, behavior, and cognition in social interactions. Frontiers in Psychology, 6, 1-16. http://doi.org/10.3389/fpsyg.2015.01752 
Steindl, C., Jonas, E., Sittenthaler, S., Traut-Mattausch, E., \& Greenberg, J. (2015).

Understanding psychological reactance: New developments and findings. Zeitschrift für Psychologie, 223, 205-214. http://doi.org/10.1027/2151-2604/a000222

Suitor, J. J., \& Pillemer, K. (1994). Family caregiving and marital satisfaction: Findings from a 1-year panel study of women caring for parents with dementia. Journal of Marriage and Family, 56, 681-690. http://doi.org/10.2307/352878

Theiss, J. A., \& Solomon, D. H. (2006a). A relational turbulence model of communication about irritations in romantic relationships. Communication Research, 33, 391-418. http://doi.org/10.1177/0093650206291482

Theiss, J. A., \& Solomon, D. H. (2006b). Coupling longitudinal data and multilevel modeling to examine the antecedents and consequences of jealousy experiences in romantic relationships: A test of the relational turbulence model. Human Communication Research, 32, 469-503. http://doi.org/10.1111/j.1468-2958.2006.00284.x

Worley, T. R., \& Samp, J. A. (2016). Gendered associations of decision-making power, topic avoidance, and relational satisfaction: A differential influence model. Communication Reports, 29(1), 1-12. http://doi.org/10.1080/08934215.2015.1025988

$\mathrm{Xu}, \mathrm{J}$. (2017). The impact of locus of control and controlling language on psychological reactance and ad effectiveness in health communication. Health Communication, 32, 1463-1471. http://doi.org/10.1080/10410236.2016.1230807 
Figure 1

Serial Mediation Model with Perceived Freedom Threat and Reactance as Proposed Mediators of Partner Inference Effects on Directness of Communication about Irritation (see Table 3 for Estimates)

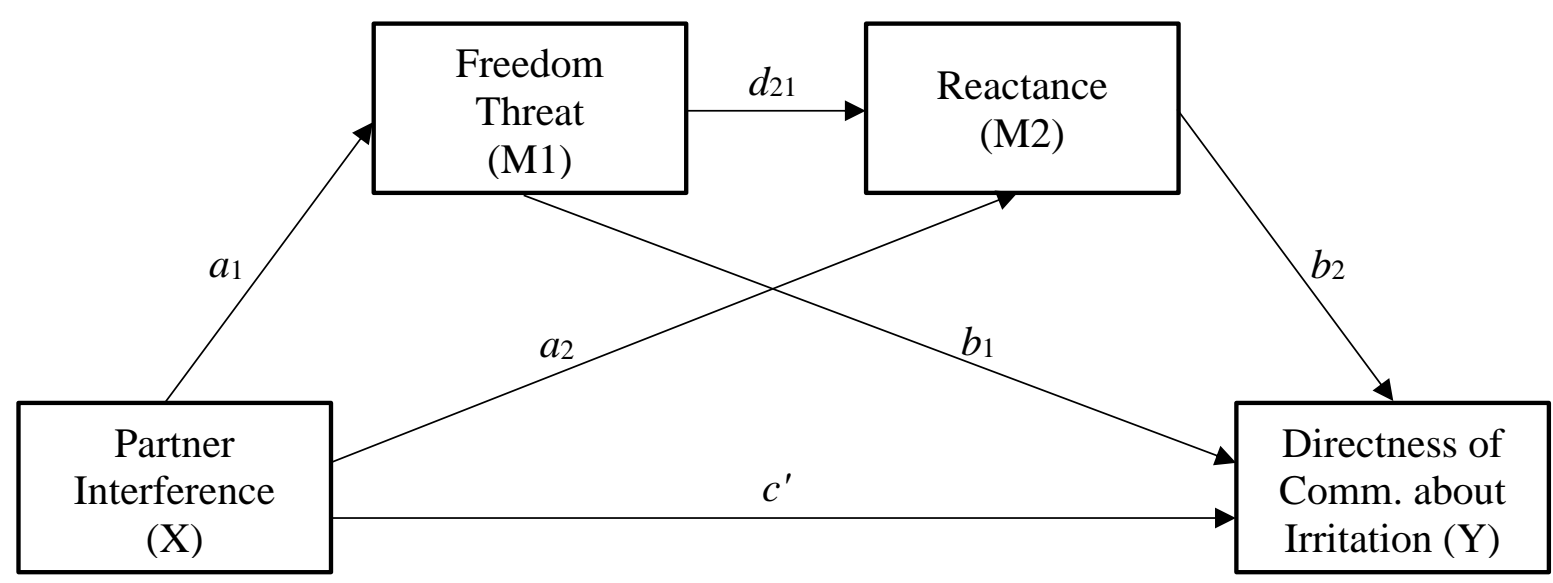

Note. Ordinary Least Squares Path Analysis using PROCESS Model 6. Covariates are not pictured for simplicity, but statistical controls include relationship satisfaction, gender, marital status, hours per week providing care, whether one's romantic partner helps provide care, current caregiving status, and number of family members providing care on M1, M2, and Y. 
Table 1

Participant Demographics $(N=187)$

\begin{tabular}{|c|c|c|c|c|c|}
\hline Characteristic & $M(S D)$ & Min & Max & $n$ & $\%$ \\
\hline Age of participant & $37.78(11.48)$ & 18 & 75 & & \\
\hline \multicolumn{6}{|l|}{ Gender identity } \\
\hline Woman & & & & 103 & 55.1 \\
\hline Man & & & & 83 & 44.4 \\
\hline \multicolumn{6}{|l|}{ Ethnicity ${ }^{\dagger}$} \\
\hline Asian & & & & 16 & 8.6 \\
\hline Black or African American & & & & 24 & 12.8 \\
\hline Hispanic or Latina/Latino & & & & 11 & 5.9 \\
\hline Middle Eastern & & & & 2 & 1.1 \\
\hline $\begin{array}{l}\text { Pacific Islander, Native } \\
\text { American, or Alaska Native }\end{array}$ & & & & 3 & 1.6 \\
\hline White & & & & 135 & 72.2 \\
\hline \multicolumn{6}{|l|}{ Employment status } \\
\hline Work full-time & & & & 125 & 66.8 \\
\hline Work part-time & & & & 31 & 16.6 \\
\hline Student & & & & 11 & 5.9 \\
\hline Not employed or retired & & & & 20 & 10.7 \\
\hline \multicolumn{6}{|l|}{ Annual income } \\
\hline Less than $\$ 11,000$ & & & & 2 & 1.1 \\
\hline$\$ 11,000-\$ 30,000$ & & & & 24 & 12.8 \\
\hline$\$ 31,000-\$ 50,000$ & & & & 47 & 25.1 \\
\hline$\$ 51,000-\$ 75,000$ & & & & 50 & 26.7 \\
\hline$\$ 76,000-\$ 100,000$ & & & & 32 & 17.1 \\
\hline$\$ 101,000-\$ 150,000$ & & & & 16 & 8.6 \\
\hline More than $\$ 150,000$ & & & & 14 & 7.5 \\
\hline \multicolumn{6}{|l|}{ Sexual orientation } \\
\hline Heterosexual & & & & 161 & 86.1 \\
\hline Gay or Lesbian & & & & 10 & 5.3 \\
\hline Bisexual & & & & 15 & 8.0 \\
\hline Age of romantic partner & $38.52(11.67)$ & 18 & 75 & & \\
\hline \multicolumn{6}{|l|}{ Married? } \\
\hline Yes & & & & 108 & 57.8 \\
\hline No & & & & 79 & 42.2 \\
\hline Age of care recipient & $71.06(14.91)$ & 31 & 96 & & \\
\hline \multicolumn{6}{|l|}{ Relationship to care recipient ${ }^{\dagger}$} \\
\hline $\begin{array}{l}\text { Parent (including stepparents } \\
\text { and in-laws) }\end{array}$ & & & & 124 & 66.3 \\
\hline Grandparent & & & & 40 & 21.4 \\
\hline Sibling & & & & 14 & 7.5 \\
\hline Aunt, uncle, or cousin & & & & 13 & 7.0 \\
\hline $\begin{array}{l}\text { Number of family members } \\
\text { providing care }\end{array}$ & $2.12(2.36)$ & 0 & 15 & & \\
\hline
\end{tabular}

${ }^{\dagger}$ Participants could select more than one category 
Table 2

Correlation Matrix for Study Variables

\begin{tabular}{|c|c|c|c|c|c|c|c|c|c|c|c|c|}
\hline \multicolumn{2}{|c|}{ Variable } & 1 & 2 & 3 & 4 & 5 & 6 & 7 & 8 & 9 & 10 & 11 \\
\hline 1 & Partner interference & - & & & & & & & & & & \\
\hline 2 & Freedom threat & $.89 * * *$ & - & & & & & & & & & \\
\hline 3 & Reactance & $.70 * * *$ & $.71 * * *$ & - & & & & & & & & \\
\hline 4 & $\begin{array}{l}\text { Directness of } \\
\text { communication } \\
\text { about irritation }\end{array}$ & $.34 * * *$ & $.37 * * *$ & $.18^{*}$ & - & & & & & & & \\
\hline 5 & $\begin{array}{l}\text { Relationship } \\
\text { satisfaction }\end{array}$ & $-.30 * * *$ & $-.25 * *$ & $-.51 * * *$ & -.13 & - & & & & & & \\
\hline 6 & Gender identity & -.01 & -.05 & .03 & $.15^{*}$ & -.14 & - & & & & & \\
\hline 7 & Marital status & .10 & .09 & .02 & -.04 & $.23 * *$ & .13 & - & & & & \\
\hline 8 & $\begin{array}{l}\text { Hours per week } \\
\text { providing care }\end{array}$ & -.05 & -.14 & -.08 & -.02 & $-.19 *$ & .09 & $-.21 * *$ & - & & & \\
\hline 9 & $\begin{array}{l}\text { Whether partner } \\
\text { provides care }\end{array}$ & .13 & $.19 *$ & $.15^{*}$ & .04 & -.05 & $-.15 *$ & -.07 & $.22 * *$ & - & & \\
\hline 10 & $\begin{array}{l}\text { Current caregiving } \\
\text { status }\end{array}$ & .06 & .08 & .00 & .00 & .06 & -.03 & $.18^{*}$ & .03 & .13 & - & \\
\hline 11 & $\begin{array}{l}\text { Number of family } \\
\text { members providing } \\
\text { care }\end{array}$ & -.13 & -.13 & -.10 & $-.15^{*}$ & .08 & .08 & .13 & -.12 & -.08 & -.02 & - \\
\hline
\end{tabular}

Note. $* p<.05 . * * p<.01 . * * * p<.001$. Two-tailed. Gender identity: $1=$ woman, $0=$ man; marital status, $1=$ married, $0=$ not married; partner providing care: $1=$ yes, $0=$ no; current caregiving status: $1=$ current caregiver, $0=$ former caregiver. 
Table 3

Regression Coefficients, Standard Errors, and Model Summary Statistics for Serial Mediation Model (H1-H4)

\begin{tabular}{|c|c|c|c|c|c|c|c|c|c|c|c|c|}
\hline \multirow[b]{3}{*}{ Antecedent } & \multicolumn{12}{|c|}{ Consequent } \\
\hline & & \multicolumn{3}{|c|}{ Freedom threat (M1) } & & \multicolumn{3}{|c|}{ Reactance (M2) } & & \multicolumn{3}{|c|}{$\operatorname{DCI}(\mathrm{Y})$} \\
\hline & & Coeff. & $S E$ & $p$ & & Coeff. & $S E$ & $p$ & & Coeff. & $S E$ & $p$ \\
\hline $\begin{array}{l}\text { Partner } \\
\text { interference (X) }\end{array}$ & $a_{1}$ & .80 & .04 & $<.001$ & $a_{2}$ & 1.17 & .58 & .05 & $c^{\prime}$ & .11 & .14 & .43 \\
\hline $\begin{array}{l}\text { Freedom threat } \\
\text { (M1) }\end{array}$ & & - & - & - & $d_{21}$ & 2.51 & .63 & $<.001$ & $b_{1}$ & .39 & .15 & .01 \\
\hline Reactance (M2) & & - & - & - & & - & - & - & $b_{2}$ & -.04 & .02 & .02 \\
\hline $\begin{array}{l}\text { Relationship } \\
\text { satisfaction }\end{array}$ & & .03 & .05 & .65 & & -2.99 & .43 & $<.001$ & & -.11 & .11 & .34 \\
\hline Gender identity & & .09 & .13 & .52 & & .19 & 1.07 & .86 & & .63 & .25 & .01 \\
\hline Marital status & & -.08 & .14 & .56 & & .96 & 1.12 & .39 & & -.29 & .26 & .27 \\
\hline $\begin{array}{l}\text { Hours per week } \\
\text { providing care }\end{array}$ & & -.01 & .00 & $<.01$ & & -.06 & .04 & .08 & & -.01 & .01 & .45 \\
\hline $\begin{array}{l}\text { Whether partner } \\
\text { provides care }\end{array}$ & & .41 & .14 & $<.01$ & & 1.09 & 1.15 & .34 & & .00 & .27 & .99 \\
\hline $\begin{array}{l}\text { Current } \\
\text { caregiving status }\end{array}$ & & .04 & .18 & .83 & & -.99 & 1.45 & .50 & & -.08 & .34 & .81 \\
\hline $\begin{array}{l}\text { Number of } \\
\text { family members } \\
\text { providing care }\end{array}$ & & -.01 & .03 & .83 & & .01 & .22 & .97 & & -.06 & .05 & .21 \\
\hline
\end{tabular}




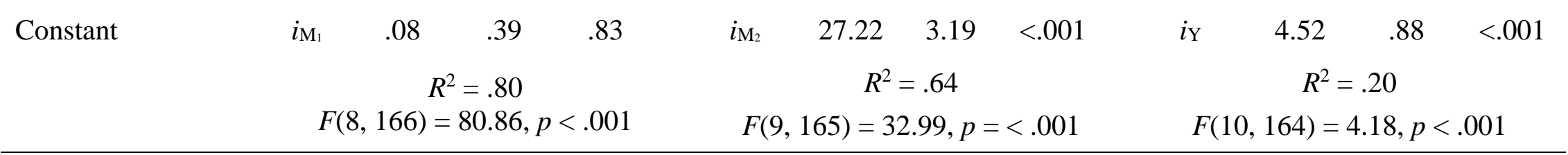

Note. Path coefficients are unstandardized. DCI = Directness of communication about irritation. 